\title{
LONTARAK; SUMBER BELAJAR SEJARAH LOKAL SULAWESI SELATAN
}

\author{
Bahri, Andi Dewi Riang Tati \\ Universitas Negeri Makassar \\ bahri@unm.ac.id,madilfa79@gmail.com
}

\begin{abstract}
Abstrak
Lontarak adalah naskah yang memuat berbagai aspek kebudayaan Bugis sejak zaman dahulu sampai sekarang. Lontarak berfungsi mewariskan adat kebudayaan dalam bentuk asli. Lontarak salah satu media yang bertahan mewariskan kebudayaan dalam keasliannya. Lontarak, terdiri dari berbagai jenis dan isi Lontarak adalah pappangajak atau pesan yang terkait dengan berbagai bidang kehidupan. Lontarak merupakan sumber belajar sejarah karena berisi tentang peristiwa sejarah yang memiliki nilai-nilai yang dapat diintegrasikan dalam berbagai kehidupan. Rekomendasi dari penelitian ini adalah lontarak dapat dijadikan sumber belajar bagi masyarakat Sulawesi Selatan pada semua jenjang pendidikan.
\end{abstract}

Kata kunci: lontarak, sumber belajar, sejarah lokal

\begin{abstract}
Lontarak is a text that contains various aspects of Bugis culture from ancient times to the present. The function of lontarak is to inherit cultural customs in their original form. Lontarak is one of the mediums that has survived the inheritance of culture in its authenticity. Lontarak, consisting of various types which have contents of a pappangajak or message related to various fields of life. Lontarak is a source of learning history because it contains historical events that have values that can be integrated in various lives. The recommendation of this study is that Lontarak can be used as a source of learning for the people of South Sulawesi at all levels of education.
\end{abstract}

Keywords: lontarak, source of learning, local history

\section{PENDAHULUAN}

Seperti pada umumnya di Indonesia, di wilayah Sulawesi Selatan (pada masa kerajaan) telah dibuktikan bahwa tradisi lisan telah berjalan cukup lama. Pada awalnya, kesusastraan suci orang Bugis diwarisi secara lisan, kemudian diabadikan dalam karya tulis berupa mantera-mantera dan kepercayaan-kepercayaan mitologi. Perkembangan selanjutnya, hasil 
kesusatraan yang bersifat keduniaan juga berkembang sesuai dengan perkembangan lontarak dan sikap hidup masyarakat serta kebudayaannya (Yusuf, 2012).

Lontarak atau dalam Bahasa Bugis dan Makassar disebut sure attoriolong (istilah klasik), tulisan yang menceritakan peristiwa orang dahulu kala. Arti lontara memiliki kesamaan arti dan makna kronik yang menceritakan peristiwa yang ditulis secara kronologis dan teratur. Lontarak merupakan wadah bagi orang Bugis Makassar mencatatkan berbagai peristiwa dalam kehidupannya pada masa dahulu kala (Mattulada, 1971). Pendapat lain mengatakan lontarak dari kata ruang talak (Makassar) yang secara harapiah berarti daun pohon. Lontarak beraksara Bugis-Makassar yang disebut urupu sulapa eppa (Bugis) urupu sulapa appaka (Makassar) yang berarti segi empat.

Lontarak merupakan warisan sejarah dan budaya masyarakat Bugis Makassar yang memiliki nilai yang sangat tinggi. Berbagai falsafah dan petuah (pappangaja; Bugis) tertuang dalam Lontarak. Lontarak merupakan manuskrip yang ditulis di atas daun lontar yang dibubuhi cairan berwarna hitam. Lontarak adalah manuskrip yang aslinya ditulis dengan alat yang tajam di atas daun lontar. Setelah ditemukannya kertas sebagai media tulis, nama lontarak masih tetap digunakan.

Diawal ditemukannya, lontarak yang merupakan kesusatraan suci orang Bugis Makassar diwariskan secara lisan, namun pada perkembangannya tersurat yang berisi pengetahuan-pengetahuan klasik, kepercayaan dan mantera-mantera. Perkembangan selanjutnya pada zaman kerajaan-kerajaan munculnya tokoh pemikir (to acca) membawa pengaruh yang cukup mendasar pada isi lontarak. Bidang pemerintahan, 
sosial dan ekonomu dan bidang hidup lainnya telah banyak menghiasi isi lontarak sebagai rel yang mengatur kerajaan-kerajaan di Sulawesi Selatan.

Naskah lontarak, termasuk naskah I Lagaligo, yang merupakan naskah yang tua yang diperkirakan ditulis pada tahun $900 \mathrm{M}$ pada masa pemerintahan raja Batara Lattu, ketika putra Sawerigading yang bernama I Lagaligo. Kemudian penulis dalam istana memberi nama buku itu I Lagaligo atas anjuran Batara Lattu. I Lagaligo tebalnya \pm 6000 halaman, buku tersebut berada di Universitas Leiden Negeri Belanda (Lewa, 1984). B. F Mathes maupun R. Areru berpendapat bahwa ketika I Lagaligo ditulis, orang Bugis-Makassar masih menempati pesisir pantai dan belum masuk ke daerah-daerah pegunungan (Abidin, 1970). Lagaligo menggambarkan keadaan Kerajaan Bugis pada masa sebelum abad XIV atau masa sebelum lontarak.

Berbagai lontarak yang tersebar di wilayah Sulawesi Selatan hingga saat ini belum diketahui secara pasti awal keberadaannya. Namun menurut Mattulada, didasarkan pada isi galigo bahwa lontarak, dilihat dari tema-tema di dalam Galigo besar kemungkinan lontarak ada sejak abad ke 7 sampai abad 12, yakni pada masa perkembangan dan akhir kejayaan kerajaan-kerajaan Hindu Budha di Nusantara, seperti Sriwijaya dan Majapahit. Dalam Sejarah Gowa dijelaskan tentang pentingnya lontarak karena dapat menceritakan kepemimpinan raja-raja untuk diketahui anak cucu dikemudian hari. Sementara Mattulada lebih menekankan pada arti penting lontarak sebagai pangkal kepercayaan dan pandangan mitologi orang Bugis Makassar.

Islamisasi di Sulawesi Selatan cenderung menulis ajaran Islam (Alquran) dalam lontara, sehingga ditemukan beberapa lontarak yang 
isinya menggunakan bahasa Arab. Lontarak tidak hanya catatan yang disalin dengan aksara Bugis diatas daun lontarak, akan tetapi juga catatan yang ditulis dengan pena diatas kertas baik menggunakan aksara Bugis maupun Bahasa Arab. Setelah orang Sulawesi Selatan menggunakan kertas dan daun lontarak yang digunakan yang dibuat dari lidi atau ijuk, serta air perasan buah ciping (sejenis kacang-kacangan) sebagai tintanya, kata lontarak tetap digunakan.

\section{METODE}

Jenis penelitian yang digunakan adalah penelitian kualitatif yang bertujuan untuk memahami, atau menafsirkan sebuah fenomena (Kuper, Scott Reeves, Wendy Levinson, 2008;740). Penelitian sejarah digunakan untuk mengungkap peristiwa sejarah secara kronologis. Adapun rangkaian penelitian sejarah menurut beberapa ahli. Langkah-langkah penelitian sejarah memiliki 3 langkah menurut Grigg: (1) penelitian, atau identifikasi dan lokasi sumber dan pemilihan bukti dari ini; (2) analisis, biasanya dibagi menjadi kritik eksternal dan internal; dan (3) sintesis, atau interpretasi. Golder mengemukakan penelitian historis memiliki lima langkah-langkah: (1) pilih topik dan kumpulkan bukti, (2) evaluasi secara kritis sumber-sumber bukti, (3) secara kritis mengevaluasi bukti, (4) menganalisis dan menafsirkan bukti, dan (5) menyajikan bukti dan kesimpulan. Smith dan Lux mengemukakan bahwa metode penelitian historis sebagai sebagai penelitian kualitatif dan interpretatif dengan tiga langkah: (1) penyelidikan, (2) sintesis, dan (3) interpretasi (Porra, 2014; $553)$. 


\section{PEMBAHASAN}

\section{Lontarak dan Ajarannya}

Berdasarkan hasil penelitian dari berbagai sumber yang didapatkan, maka peneliti menyimpulkan jenis-jenis lontarak yang ada di Sulawesi Selatan beserta contoh isi dari lontarak tersebut adalah sebagai berikut:

Lontarak papaseng ialah kumpulan amanat atau pesan orang bijaksana, yang ditulis dan disuratkan kemudian ditulis secara turun temurun. Paseng semacam ini jadikan kaidah hidup dalam masyarakat. Paseng adakalanya berisi cara pelaksanaan pemerintahan yang baik, dan lain sebagainya. Salah satu contoh dari paseng tersebut adalah pappaseng Nenek Allomo, seperti tertera berikut: tellu tau kupaseng: Arung Mangkau e, pabnicara e, suroe, ajakpuramucapak I lempu e O arung mangkau, Malempuko Numadeceng bicara, mumagetteng, Apak ia riaseng e malempu, madeceng bicara, leperi sungek, apaktemmate lempu e, teppettu maompengge teppolo masellomoe. Terjemahan: kuberpesan tiga golongan: Maha Raja, pabbicara dan pesuruh, jangan sekali-kali engkau meremhkan kejujuran itu maha raja. Berlaku jujurlah serta peliharalah tutur katamu, engkau harus tegas, sebaba yang di sebut kejujuran, tutur kata yang baik itu memanjangkan usia. Oleh karena tidak akan mati kejujuran itu takkan putus yang kendur, takkan patah yang lentur.

Lontarak paggalung, ialah lontarak yang isinya menjelaskan keadaankeadaan cuaca keadaan musim hujan, tanaman-tanaman yang baik di tanam. Lontarak yang berukuran kecil yang biasanya tidak banyak isinya dan lembarannya dinamakan sure-sure. Sure-sure bermacam-macam jenisnya, misalnya: 1) Sure eja-eja (gadis-gadis remaja). Sure-sure eja mengandung nyanyian yang biasanya dinyanyikan pada waktu naik rumah baru, mengadakan perkawinan dan perjalananan, upacara penting 
lainnya. 2) Sure-surekotika (astrologi). Sure-sure kotika berisi keterangan mengenai hari baik dan hari buruk, langkah baik atau langkah buruk dalam suatu perjalanan untung ruginya perdagangan, cocok tidaknya pasangan mempelai, ayam apa yang berbulu yang menang apabila disabung dan lain-lain.

Lontarak pattuangan ini berisi masalah-masalah kehidupan pribadi, keluarga dan tetangga, juga berisi masalah umum yang terjadi setiap waktu, seperti kematian dan kelahiran. Kronik adek yang mengandung catatan hukum adat. Contoh: akko engka tau ri uno riwirinna aleke, pura masebbuni tapauno na engka tau irapi malai agaganna to riwuno e ia natu masapu, na mauni de aga - aga nala nasabak ia ri rapi, ia natu masapu to ri rapi e koro. Terjemahan: Kalau ada orang yang dibunuh di pinggir hutan kemudian pembunuh bersembunyi dan setelah itu ada orang lain yang kedapatan mengambil harta orang yang terbunuh itu, maka meskipun belum ada harta yang diambilnya, orang itulah yang dituduh melakukan pembunuhan.

Lontarak pangajak ialah kumpulan nasehat yang diberikan oleh orang tua kepada anak dan keturunannya. Adakalanya lontarak pangajak ini merupakan rentetan ceritera atau hikayat. Contoh, pangajak; makkedai sininna tommissengnge na ia tamranna tari agellie ri Allah taalah eppak I rupanna, mula-mulanna maega pangisengenna, na padek araing nekek na, matellunna rekko arainngi arajanna, na pedek araing napakaraja alena ma eppana rekko ri warengi umuruk ma lamoek na pedek masaro kallang. Terjemahan: berkata semua orang alim, tanda orang yang di benci oleh Allah ada empat perkara. Pertama bila ilmunya banyak semakin meningkat kejahatannya, kedua bila meningkat kekayaannya meningkat pula, ketiga 
bila meningkat pangkatnya maka meningkat pula sifatnya keangkuhannya, keempat bila diberi umur yang panjang makin menningkat pula ketamakannya.

Lontarak attoriolong ialah sekumpulan catatan mengenai asal-usul (silsilah) keturunan dari raja-raja bangsawan dan keluarga tertentu dari attoriolong ini biasa diambil bahan-bahan untuk menyusun sejarah, disamping itu attoriolong berfungsi sebagai catatan peristiwa yang lalu dilakukan atau dialami orang dahulu kala. Lontarak ini banyak disimpan oleh orang-orang terkemuka.

\section{Lontarak Sebagai Sumber Belajar}

Mengenai sejarah awal munculnya tulisan lontarak itu sampai sekarang masih simpang siur siapa yang menciptakan aksara BugisMakassar. Dalam buku Sedjarah Goa ditemukan suatu kalimat bahwa perlunya diceritakan raja-raja (Gowa) purbakala, supaya anak cucunya dapat mengenal mereka.

Iangku mabassung, iangku maweke-weke angngrangi, ambilang-bilangi karaeng rioloa, lulu gulang-gulanga, assi palakkaya, bulaeng napaninga, ratu sikolaka, nikamallakannaji nikaluppai riana'na, ricucunna, ritubokonna; kapunna taniasseng, ruai kodina, kisa'ringkai kalenta karaengdudu, nakanaka tau ipantaraka tau bawang-dudu (Wolhoof dan Abdulrahim, tt). Artinya: semoga janganlah saya menjadi busung, semoga janganlah saya menjadi binasa. Gulang-gulanga "palakkaya", emas dilebur mata utama rantai, hanya karena dikuatirkan agar mereka jangan dilupakan oleh anak, cucunya dan keturunannya (maka kelakuannya), karena bila (mereka) tidak diketahui, tidak diketahui, dua keburukannya; atau kita merasa diri kita maharaja (terlalu meninggi-ninggikan keturunan), atau orang lain 
menyangka kita orang hina (karena tidak kenal sejarah raja-rajanya atau tidak keturunan raja.

Pendapat tersebut di atas mengindikasikan bahwa di Kerajaan Gowa telah ada usaha untuk memperkenalkan sejarah Kerajaan Gowa kepada anak cucu mereka dengan menceritakannya, namun belum disebutkan bahwa hal tersebut dilakukan dengan dengan menggunakan tulisan ataupun catatan terhadap suatu peristiwa, kepemimpinan raja-raja dan hal lainnya yang terkait dengan Kerajaan Gowa. Baru pada masa pemerintahan raja ke IX Tumaparisi Kallonna, syahbanda Daeng Pametta memperkenalkan huruf Lontara dalam menuliskan berbagai hal tentang Kerajaan Gowa yang disebut lontara bilang. Sebagaimana yang termuat dalam Sejarah Gowa sebagai berikut:

Iapa anne Karaeng uru mapparek rapang-bitjara, timu-timu ribunduka; sabannarak naminne Karaeng nikana I Daeng Pamattek ampareki lontarak mangkasaraka. Artinya; baru Raja inilah yang mula-mula membuat undang undang dan peraturan perang; syahbandar raja ini bernama I Daeng Pamattek, dia syahbandar dan dia juga Tumilalang (Perdana Menteri), dan Daeng Pamattek ini jugalah yang membuat huruf Makassar (Wolhoof dan Abdulrahim, tt).

Penggunaan istilah sulapak eppak pada abjad Bugis Makassar hanya merupakan usaha untuk menafsirkan filosofi sulapak eppak yang sarat makna. Berbagai kisah tentang Bugis Kuno sudah ditulis dalam berbagai jenis huruf. Setelah B.F Matthes B. F. Matthes mendalami karya-karya klasik Bugis-Makassar, wujud alphabet baru dikenal sulapak eppa menjadi baku penggunaannya terutama untuk memudahkan bentuknya dalam pencetakan. Setelah berbagai naskah ditulis menggunakan alphabet 
sulapak eppa. Penggunaan alphabet ini kemudian meluas, termasuk misi Matthes untuk menerbitkan Injil dalam terjemah bahasa Bugis, naskahnaskah keagamaan lainnya, dan kisah-kisah yang erat hubungannya dengan penyebaran agama yang dapat dibaca secara luas (Yusuf, 2012).

Terdapat 3028 naskah yang telah dimicrofilmkan di Universitas Hasanuddin (UNHAS), beberapa naskah menjadi bukti adanya penulisan menggunakan huruf Bugis pra Matthes dan menggunakan alphabet Bugis. Sedangkan Noordyn berpendapat terkait dengan muasal aksara Bugis, dari strukturnya berkesimpulan bahwa lontarak berasal dari Bahasa India, karena ada kemiripan dalam strukturnya. Sementara K. F. Holle dan R. F. Mills, sebagaimana dikutip Fakhruddin, bahwa aksara lontarak dapat dibagi atas lontara lama dan lontarak baru. Aksara lontarak lama terdapat persamaan dengan aksara Jawa (Kawi), sedangkan aksara baru lebih mirip dengan aksara Sumatra (Rejang, Lampung, Pasemah) (Yusuf, 2012).

Berbagai peristiwa sejarah termuat dalam lontarak, namun tidak dipungkiri mempunyai fiksi yang menyebabkan isi lontarak kurang dipercaya oleh masyarakat. Menurut Cence lontarak sebagai permulaan penulisan unsur sejarah yang termuat dalam lontarak memuat beberapa berita peristiwa penting, catatan permulaan itu tersebar kemudian dihimpun dalam suatu koleksi kecil yang diberi penanggalan dan terkadang si penulis memberi tanggal pada saat ditulis atau disalin, salah satu contoh singkat tapi tidak mempunyai tanggal yang mempunyai sumber sejarah yaitu perubahan nama Kerajaan Cina menjadi Pammana atas amanat Datu Cina XX Lasangaji pada permulaan abad XV (Attahilla, 1985). Catatan lontarak lainnya yang mengandung unsur sejarah yaitu 
kisah perjuangan Lamadukkelleng (1714-1756), episode kepahlawanan tersebut dilengkapi tanggal yang menurut Nurduyn tidak tercantum dalam kronik. Peristiwa sejarah perjuangan Lamaddukelleng dimuat dengan lengkap dalam lontarak Wajo (Hatta, 1970).

Penggunaan kata lontarak dalam Sejarah Gowa ditemukaan dalam pernyataan, misalnya te'napa lontara, nipailalang lontarak, nipari lontarak dan pallontarak. Kata lontarak juga dapat ditemukan dalam Sedjarah Goa tentang penggunaan istilah lontarak dengan rangkaian kata yang berbeda digunakan, seperti te'napa lontara, nipailalang lontarak, nipari lontarak dan palontarak. Penggunaan kata lontarak pada kalimat, seperti; nipailalang lontarak: "teai nipailalang lontarak kanakanaya ri bunduka; iaji niparilontarak makbunduna. Artinya; yang ditulis pada lontarak bukan uraian tentang peperangan, tetapi yang ditulis adalah hanya hal-hal peperangan. Sementara kata pallontarak ditemukan dalam kalimat berikut: Iapa makgauk nauru niak ballak niukiri, namandekde Mangkasaraka tobok, nanijannangi parauk anak sappuka, Nauru niak juru tulisik, palontarak, paparada bulaeng, dacing". Artinya; baru pada masa pemerintahan Tunijallo yang merupakan raja ke VIII ada rumah yang diukir dan orang Makassar sudah mengetahui cara menempa keris, pembuat anak panah, ada juru tulis, penulis sejarah, penulis sejarah, tukang cet perada emas dan dacin.

Dalam kajian pustaka yang dilakukan oleh peneliti dalam lontarak tergambarkan berbagai aspek kehidupan, misalnya dalam kehidupan sosial, nilai kejujuran dan keadilan seharusnya dimiliki setiap aparat atau pejabat pemerintah maupun masyarakat. Dalam lontarak termuat pesan dari Nenek Mallomo yang berbunyi: Aku berpesan kepada tiga golongan maha raja, pa'bicara, pesuru. Jangan sekali-kali engkau meremehkan kejujuran 
itu, hai maha raja. Berlaku jujurlah serta peliharalah tutur katamu, engkau harus tegas sebab yang disebut kejujuran tutur kata itu memanjakan usia. Oleh karena tak akan mati kejujuran itu tak akan putus yang kendur, tak akan patah yang lentur (Halim, 1978). Dalam kehidupan politik, berbagai hal telah termuat dalam lontarak, misalnya disebutkan pentingnya keberadaan lembaga politik (lembaga adat) seperti pakkatani adek atau pampawa adek (pemangku adat). Dalam bidang ilmu pengetahuan dan tekhnologi pun terurai ilmu pelayaran dalam lontara amanagappa (Tobing, 1977).

Lontarak sebagai peninggalan sejarah dan budaya masyarakat Sulawesi Selatan memberikan pengaruh dalam berbagai bidang kehidupan bagi masyarakat Sulawesi Selatan. Salah satu peran yang dimaksud adalah lontarak digunakan sebagai sumber belajar sejarah lokal. Dalam hasil penelitian lapangan yang dilaksanakan, Lembaga-lembaga Pendidikan di Sulawesi Selatan menjadikan lontarak sebagai sumber belajar.

Salah satu usaha menjadikan lontarak sebagai sumber belajar adalah menerbitkan buku-buku yang merupakan translate dari lontarak yang berbahasa daerah sehingga memudahkan guru sebagai penuntun maupun siswa sebagai pembelajar mempelajari lontarak. Mata pelajaran bahasa daerah di Sekolah Dasar dan Sekolah Menengah Pertama, menggunakan aksara lontarak menjadi modal baik dalam melestarikan lontarak sebagai salah satu sumber belajar. Bahkan di sekolah-sekolah pelosok masih ada guru yang menggunakan bahasa daerah sebagai pengantar dalam pembelajaran, baik di kelas maupun dalam melaksanakan ekstra kurikuler (Surur, 1995). 
Mengintegrasikan peristiwa-peristiwa lokal dalam pembelajaran, serta mengidentifikasi makna dari peristiwa peristiwa sejarah yang termuat dalam lontarak memperkuat posisi lontarak, bukan hanya menjadi karya budaya monumental bagi masyarakat Bugis Makassar, namun menjadi sumber belajar, khususnya sejarah lokal Sulawesi Selatan. Selain itu berdirinya lembaga-lembaga Pendidikan formal yang kurikulumnya merupakan integrasi dari budaya lokal, misalnya sekolah Ugi Lamellong yang dikelola oleh Yayasan Sulapa Eppa yang diketuai oleh Ajiep Padindang. Tujuan dari sekolah ini untuk melestarikan nilai budaya dan sejarah melalui pendidikan.

Dengan menjadikan lontarak sebagai sumber belajar merupakan upaya untuk melestarikan kearifan lokal yang berakar dari perkembangan budaya lokal yang lahir sejak dahulu kala yakni sejak dibakukannya huruf lontarak Makassar oleh Daeng Pamatte sekitar tahun 1514 (Sidin, 2016). Mempelajari lontarak dibutuhkan media yang tepat sehingga diperlukan langkah inovasi media edukasi sehingga generasi millennial atau generasi zaman old memiliki ketertarikan dalam menjadikan lontarak sebagai sumber belajarnya.

Latoa adalah lontarak dalam kepustakaan dan kesastaran orang Bugis, lontarak ini berisi kumpulan dari berbagai ucapan/kutipan petuahpetuah raja dan orang Bugis Makassar yang bijaksana mengenai berbagai masalah terutama berkenaan dengan kewajiban-keawajiban raja terhadap rakyat dan sebaliknya. Latoa dijadikan tuntunan-tuntunan bagi penguasa terutama dalam menjalankan pemerintahan dan melaksanakan peradilan (Rasdiyana, 1995). 
Lontarak dinyatakan sebagai lambang kebanggaan karena merupakan identitas dan menjadi pembeda dengan kelompok lain. Lontarak sebagai sarana pendukung budaya daerah karena mengandung informasi kultural untuk membangun tatanan sosial dalam rangka memperkukuh budaya nasional. Karena pentingnya fungsi lontarak tersebut sehingga tetap dipelihara dan dilestarikan oleh masyarakat Bugis Makassar sebagai wujud kesadaran terhadap amanat UUD 1945 pasal 32 ayat 1 dan 2 yang berbunyi bahwa 1) Negara memajukan kebudayaan nasional Indonesia di tengah peradaban dunia dengan menjamin kebebasan masyarakat dalam memelihara dan mengembangkan nilai-nilai budayanya. (2) Negara menghormati dan memelihara bahasa daerah sebagai kekayaan budaya nasional. Naskah Lontarak sebagai dokumen tentang peristiwa yang berkaitan dengan orang Bugis Makassar pada masa lalu. Oleh karena itu, naskah lontarak dapat dipandang sebagai sumber informasi mengenai sejarah, budaya, sosial, dan dimensi kehidupan lainnya bagi masyarakat Bugis Makassar. Dengan demikian, dapat dinyatakan bahwa naskah lontara dipandang sebagai bahasa dari indeks budaya dan dipersepsikan sebagai pengungkapan cara berpikir, penataan pengalaman penulisnya, dan simbol budaya yang menunjukkan identitas budaya etnis.

Baik dalam kajian pustakan maupun dalam penelitian lapangan, peneliti menyimpulkan bahwa lontarak bagi masyarakat merupakan hasil sejarah dan budaya yang sarat makna. Adapun fungsinya adalah sebagai; (1) lambang jati diri, (2) lambing kebanggaan, dan (3) sarana pendukung budaya daerah. Lontarak berfungsi sebagai lambing jati diri karena termuat berbagai nilai budaya yang menjadi ciri khas masyarakat Bugis 
Makassar. Lontarak sebagai sebagai lambang kebanggaan karena telah menjadi lambang identitas suku Bugis Makassar. Sedangkan lontarak sebagai sarana pendukung budaya adalah karena dalam lontarak terdapat informasi kultural yang dapat membangun tatanan sosial dalam rangka memperkuat budaya nasional.

Naskah lontarak sebagai dokumen tentang peristiwa yang berkaitan dengan orang Bugis pada masa lalu sehingga dapat dipandang sebagai sumber informasi mengenai sejarah, sosial, dan budaya dan bidang kehidupan lainnya. Lontarak digunakan untuk mengungkapkan berbagai macam bentuk ritual, doa, dan ceritra. Dengan demikian, dapat dinyatakan bahwa naskah Lontarak dipandang sebagai bahasa dari indeks budaya dan dipersepsikan sebagai pengungkapan cara berpikir, penataan pengalaman penulisnya, dan simbol budaya yang menunjukkan identitas budaya etnis. Kenyataan tersebut mencerminkan bahwa dalam naskah lontarak, relasi bahasa, pikiran, dan perilaku memiliki hubungan yang dinamis dan signifikan. Bahasa, pikiran, dan perilaku merupakan satu entitas untuk mencapai suatu tujuan tertentu. Dalam perspektif kritis, wacana dipahami sebagai penggunaan bahasa sebagai praktik sosial. Pandangan tersebut juga dinyatakan Fairclough (1995) bahwa dimensi kewacanaan secara simultan, seperti dimensi teks berkaitan bahasa tulis, dimensi praktik wacana yang berkaitan dengan produksi dan interpretasi teks, dan dimensi praktik sosial kultural. Perubahan sosial dalam masyarakat, institusi, dan kebudayaan turut menentukan bentuk dan makna sebuah wacana.

Nilai-nilai moral dalam ceritra rakyat Bugis didukung oleh Cense (1971) menyatakan, lontarak Bugis mengandung hukum adat, adat istiadat, 
ajaran moral, dan petuah-petuah. Mattulada (1985) menemukan hukum adat disebut pangadereng yang disemangati oleh etos kerja budaya yang disebut Siri dalam sistem pemerintahan yang demokratis. Lontara sastra klasik Bugis sebagai hasil emperis Ambo Enre (1992) menunjukkan adanya nilai sosial-budaya yang dapat meningkatkan harkat dan martabat masyarakat Bugis. Sedangkan Lontarak Pau-Pau Rikadong yang dikerjakan oleh Rahim (1985) menemukan nilai esensial sebagai pedoman dan pegangan dalam kehidupan sehari-hari. Lontara sebagai naskah klasik juga telah dikaji oleh Rapi Tang (1998) tentang Lontara tolak Rumpakna Bone dengan pendekatan filologi (Jufri, 2006).

Berdasarkan hasil penelitian disimpulkan bahwa umunnya generasi milenial (muda) tidak memiliki perhatian terhadap kajian lokalitas, ada kecenderungan kurang berminat untuk mengkaji budaya lokalnya, termasuk lontarak. Pemerhati sejarah dan budaya lokal jelas prihatin dengan kondisi tersebut. Seperti yang dikemukakan oleh Andi Zainal Abidin (2003:2) menyatakan bahwa sebagian masyarakat Bugis Makassar saat ini, kurang berminat lagi membaca dan menulis tentang budaya lokal dan lebih cenderung memiliki kebiasaan menonton dan mendengar media elektorik. Disamping perhatian kurang terhadap pemberdayaan budaya lokal, juga kebijakan daerah yang kurang sungguh-sungguh mendukung hal tersebut. Dengan demikian, naskah lontarak sebagai wahana penyampaian informasi bagi masyarakat mendapatkan tantangan dan ancaman. Wahab (2003:9) juga mengungkapkan kesangsiannya, bahwa ada keraguan terhadap nilai budaya sendiri, sebagai akibat ketidakmampuan menghormati dan mengembangkan budaya daerah, termasuk lontarak. Lontarak sebagai budaya lokal memiliki derajat yang 
tinggi yang memungkinkan menjadi sumber belajar yang bernilai bagi dunia pendidikan.

\section{DAFTAR PUSTAKA}

(1). Abidin, Zainal. (1970). Lontara Sebagai Sumber Sejarah Terpendam (masa 1500-1800). Makassar: Yayasan Budaya Sul Sel.

(2). Athailla. (1985). Peristiwa Tahun-Tahun Bersejarah dari Abad ke 14-19, Ujung Pandang.

(3). Hatta, Alimuddin (1970). Perang Luwu Melawan Belanda 1906, Palopo.

(4). Kuper, Ayelet, Scott Reeves, Wendy Levinson. Qualitative Research an Introduction to Reading and Appraising Qualitative Research, Journal Education and debate (BMJ: British Medical Journal; England), Vol. 315, No. 7110, p.740, 2008.

(5). Jufri. 2006. Struktur wacana Lontara La Galigo. Pascasarjana Universitas Malang: Malang

(6). Lewa, Aminullah. (1984). Kerajaan Purbakala Bugis-Makassar. Makassar

(7). Mattulada (1971), Lontara 1971. Makassar.

(8). O.L. Tobing dkk. (1977). Hukum Pelayaran dan Perdagangan Amanagappa, Ujung Pandang.

(9). Rasdiyanah, Andi. (1995). Integrase Sistem Panggadereng dengan Sistem Syariat Islam sebagai Pandangan Hidup Orang Bugis Dalam Lontarak Latoa. Jogjakrta: UIN Sunan Kalijaga.

(10). Salim, Muh. (1978). Peranan Lontara Sebagai Sumber Pangadereng, Ujung Pandang.

(11). Siddiq, M. Taufiq (1975). Adakah Gunanya naskah-naskah lama dalam konteks pembangunan Bangsa, Ujung Pandang.

(12). Sidin, Udin Sidik. (2016). Media Edukasi Pengenalan Huruf Lontara Makassar Berbasis HTML5. Jurnal semanTIK, Vol.2, No.2, Jul-Des 2016 ISSN: 2502-8928 (Online). 
(13). Surur, Abubakar. (1995). Lektur Agama dalam Aksara Lontara Berbahasa Bugis. No. 12 Th. VII Juli/Desember 1995.

(14). Porra, Jaana, Rudy Hirschheim, Michael S. Parks. The Historical Research Method and Information Systems Research, (AIS: Finlandia) Journal of the Association for Information System (JAIS), Vol. 15, p. 553, 2014.

(15). Yusuf, Muhammad. (2012). Bahasa Bugis Dan Penulisan Tafsir Di Sulawesi Selatan. Jurnal Al- Ulum Volume. 12, Nomor 1, Juni 2012 